\title{
Pre-Service Elementary School Teachers' Awareness of Posing Mathematical Pseudo-Problems
}

\author{
Sitti Fithriani Saleh, Purwanto Purwanto, Sudirman Sudirman, Erry Hidayanto
}

\author{
Department of Mathematics Education, Faculty of Mathematics and Science, \\ Universitas Negeri Malang, Malang, Indonesia
}

\begin{abstract}
This study aimed to expose pre-service elementary school teachers' awareness of selecting and using real-life context in the problems they posed. The participants of this study were asked to create mathematical problems. The findings showed that some of the participants were more focused on the mathematical concepts and procedures, but tended to ignore the contexts of the problems proposed. As a result, they created problems using numbers and stories that are not relevant to everyday life or are termed pseudo-problems. Some of the real-problems submitted by the participants were not based on an awareness of problem-context relevance.
\end{abstract}

Keywords - pre-service elementary school teachers, problem posing, mathematical problem, real-problem, pseudo-problem

\section{Introduction}

Mathematics is closely correlated with what people do, think, and feel on a daily basis. Even though mathematical concepts can be easily found in everyday life, their objects of analysis are basically abstract [1].

DOI: $10.18421 /$ TEM93-54

https://doi.org/10.18421/TEM93-54

Corresponding author: Sitti Fithriani Saleh,

Department of Mathematics Education, Faculty of Mathematics and Science, Universitas Negeri Malang, Malang, Indonesia.

Email: st.fithriani.1603119@students.um.ac.id

Received: 01 May 2020.

Revised: 10 August 2020.

Accepted: 16 August 2020.

Published: 28 August 2020.

(cc) BY-NC-ND(C) 2020 Sitti Fithriani Saleh et al; published by UIKTEN. This work is licensed under the Creative Commons Attribution-NonCommercial-NoDerivs 4.0 License.

The article is published with Open Access at www.temjournal.com
Elementary school students at the concrete operational stage can encounter a problem when faced with abstract ideas [2], [3], [4]. Therefore, the teacher needs to adjust the abstract nature of mathematics to the students' level of understanding by utilizing concrete objects or realia around the students. The teacher can, for instance, introduce natural numbers using fingers or family members as an analogy, teach addition or subtraction by manipulating objects such as marbles or ice cream sticks, introduce a circle by showing a ring or a bicycle wheel. Connecting mathematical concepts with real-life contexts can make mathematics more meaningful [5], [6].

Mathematical problems given by teachers should also be linked with everyday life contexts. The mathematical problems that contain everyday life contexts could attract students' interest in solving the problems and encourage them to apply their prior knowledge and experiences in problem-solving. The teachers need to be selective in choosing or making mathematical problems that will be given to students. Good problems will provide an opportunity for students to strengthen, expand, and stimulate their understanding of a concept [7], [8].

A great number of interesting mathematical problems can be easily found in books or on the internet. However, there is no guarantee that these problems are appropriate for developing student comprehension of a particular mathematical concept. For instance, the problem "if each spider has three pairs of legs, how many feet do five spiders have?" fails to explain the object reality because this problem puts emphasis only on the mathematical numbers and thus ignores the fact that a real spider has four pairs of legs. In addition, the difference between the following word problems which involve the same operation of 25 divided by 4 , may further explain the concept of appropriacy. These problems were submitted by the elementary school teachers studied in [9]. The first word problem was, "There are four plates and 25 cookies. How many cookies can be put onto each plate equally?", while the 
second word problem was, "25 students are going on a trip in 4 vehicles. How many students will be in each car?". In solving the first problem, the elementary school students had to imagine how to divide a piece of cake left into four equal parts and put each of them on the dishes so that each dish will serve $6 \frac{1}{4}$ pieces of cake. Yet, the answer to the second problem is " 6 or 7 " or " 6 with a remainder of 1 " because it is impossible to divide a person into four equal parts. Given these contexts, the first word problem is considered more appropriate to teach elementary students about the concept of a division with remainders compared to the second problem which used human beings as the object. [10] also found pre-service teachers who create story problems like the second problem and identified it as an error.

In problem solving, learners are required to connect their knowledge and experiences to the context of the problem [11], [12]. The teachers, thus, need to be selective of the problems that are going to be presented to the students. In relation to problems that contain real-life context, teachers have to focus not only on the mathematical concepts and language used in the problems but also on the object reality. Einstein and Infeld state that problem formulation is often more essential than the solution (as cited in [13], p. 88). Training and habituation are needed to produce polished problems with minimum errors either in the mathematical concepts, language, or appropriacy. Pre-service teachers have to be served with an opportunity to develop the ability to present such problems to support student mathematical learning [8], [13], [14].

Previous studies showed various classifications of problem posing in terms of the structure of the problem [15], [16], the cognitive processes involved in problem posing [17], [18], as well as difficulties encountered in posing problems [19], [20]. [21] and [22] established the classification of problem posing activities. [21] suggested three forms of cognitive activity, namely pre-solution posing (proposing an original problem based on the given situation), within-solution posing (reformulating a problem as it is being solved), and post-solution posing (modifying the goals or conditions of a problem that have been answered to form new problems). [22] classified problem posing activities based on the situation, namely free, semi-structured, or structured. A situation is called free if someone is only asked to raise a problem freely without any specific limitations. However, there are still some directions possible to bring up particular responses. The structure of the situation is open. The situation is classified as semi-structured if someone is asked to develop a new problem based on a given problem or based on specific pictures or information. The structured category occurs when someone is asked to raise a problem by reformulating the problem that has been solved as well as changing the conditions or questions of the problem provided. In this study, three mathematical concepts were presented. Participants were given the freedom to develop problems using the concepts. Hence, this study used pre-solution posing and the form of free problemposing situation.

[23] used two types of mathematical problems in his research, namely problems involving internal connections and problems involving external connections. The problems involving internal connections are mathematical problems related to links between mathematical topics. The problems involving external connections are mathematical problems concerning the use and application of mathematics in other fields or the real world. The problems involving internal connections, as well as the problems involving external connections, include real life contexts. The difference lies in the essence of the existence of the context. On problems involving internal connections, the contexts are only as a companion or complement to the story problem. On problems involving external connections, the real world or other fields outside mathematics are the focus of importance which requires mathematical concepts and procedures to solve them.

Related to mathematical connections, [8] noted that mathematical connections could be in the form of interrelationships among mathematical ideas as well as the relationship of mathematical ideas with other subjects or everyday life. Based on this, mathematical problems can be divided into mathematical problems that accommodate the context of everyday life, mathematical problems that include knowledge from subjects other than mathematics, and mathematical problems that do not contain both of them. Problems accommodate the context of everyday life can be grouped based on the relevance of the objects, the contexts of the story, and the numbers used in the problems with the reality of daily life. If the objects, the contexts of the story, or the numbers are not relevant to the fact of daily life, then the problem is categorized as a pseudoproblem. If the contexts of the story and the numbers used in a problem commonly found in everyday life, then the problem is classified as a real-problem. The classification is presented in Figure 1. and then used to sort out the problems raised by participants in this study. 


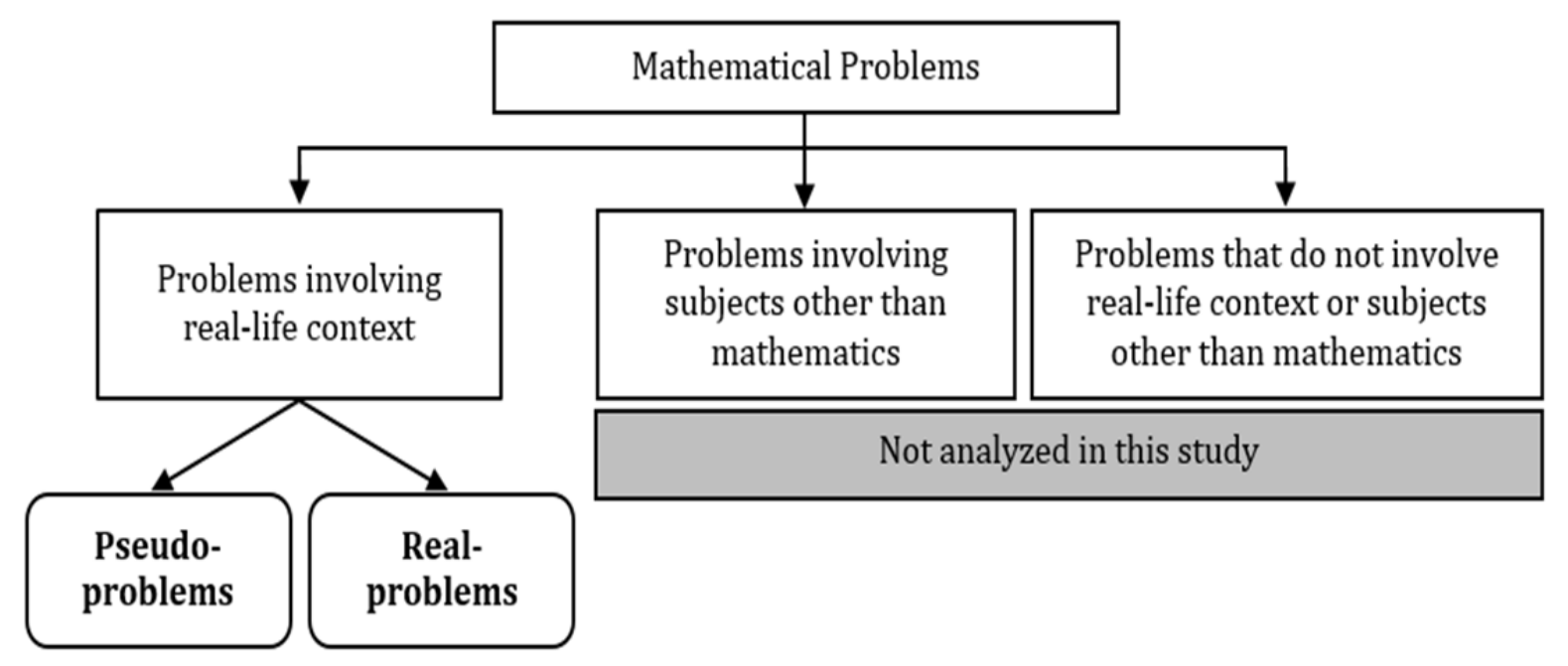

Figure 1. Problems classification

\section{The Aim of the Study}

The current study aimed to unveil pre-service elementary school teachers' awareness of selecting and using real-life context in mathematical problems. The research was not only limited to classifying the problems proposed by participants. Moreover, it explored the rationale underlying the consideration of pre-service teachers choosing objects, stories, and numbers in the mathematical problems they submitted. The choice should be relevant to the students' knowledge and experiences outside of mathematics. For elementary school students, the irrelevance between mathematics problems, especially problems that contain the context of everyday life, with their daily experiences can lead to the view that mathematics with other subjects or everyday life are not interrelated. The research question of this article is, "How aware do pre-service elementary school teachers' in choosing the numbers or the story context in mathematical problems they posed related to the daily life context?"

\section{Methodology}

\section{Research Design}

This research was qualitative and applying descriptive-approach [24], [25]. This research explores mathematical problems posed by preservice elementary school teachers and their awareness of posing problems. The participants' thought that underlies the selection and use of reallife context in the problems they created was examined in this study. Data was collected in the form of words obtained from participants' mathematical problems and their own words in the interview.

\section{Participants}

The participants of this study involved 34 preservice elementary school teachers who had been taught how to design instructional materials and how to teach mathematics to elementary school students. They were senior students at a private university in eastern Indonesia. These pre-service teachers had been accustomed to problem solving activities but were not yet familiar with problem posing. Three participants who submitted pseudo-problems and three ones who submitted real-problems were picked to conduct a semi-structured interview. They were selected based on mathematical concepts and real-life contexts used in their mathematical problems. These six participants have expressed a willingness to be interviewed.

\section{Data Collection Tools and Procedures}

The data of this research were written mathematical problems posed by participants and their remarks in the interview. Each of the participants was asked to pose mathematical problems that contain at least one of the following concepts: area of a rectangle, fraction operations, and linear equation in two variables. Mathematical problems developed based on these three concepts are more likely to accommodate real-life context. In textbooks, mathematical problems related to these three concepts are usually made in story problems containing real-life contexts. Consequently, by using them, the participants were expected to more easily get ideas to create mathematical problems that involve the context of daily life.

The free problem posing situation [22] was chosen for this task as this type of situation allowed the participants to express their ideas in presenting the 
problems freely. In other words, there was no pressure put on the participants to create problems involving the context of real life. The problems presented by the participants that do not accommodate everyday life context were not analyzed in this study. Problems were grouped into pseudo-problems and real-problems. Problems whose contexts were irrelevant to the reality in life were categorized as pseudo-problems, while problems that used stories or numbers commonly found in real life were categorized as real-problems.

Six participants were invited to do an in-depth interview related to the problems they presented earlier. The interview was carried out to explore the participants' consideration in choosing and using a particular context and numbers in a mathematical problem. The interview duration ranges differed from 15 to 30 minutes.

\section{Data Analysis}

The data analysis employed three interwoven activities, namely, data condensation, data display, and conclusion drawing [26]. The participants' mathematical problems were sorted based on the classification of the problems shown in Figure 1. The problems that do not involve real-life context were not analyzed in this study. The interview transcripts were coded to generating descriptive categories. The study used member checking to confirm the summary findings [24]. Participants were asked to check whether the narratives were reasonable and representative.

\section{Results}

Thirty-four participants submitted 45 problems. Four of them presented three problems each and three of them presented two problems each. The rest of the participants only submitted one problem each. These problems only contained one concept at a time. None of the participants presented problems that contained two or three interlinked concepts.

Classification based on problem-context relevance showed that 15 problems do not accommodate everyday life context. None of the pre-service teachers presented problems involving subjects other than mathematics. Surprisingly, thirty problems posed by the pre-service teachers were found to contain the context of real life even though they were not required to create such problems. In fact, $66.67 \%$ of the presented problems accommodate the context of real life. Table 1. maps the categories of problems involving real-life context posed by the pre-service teachers for each concept offered.
Table 1. Problems involving real-life context

\begin{tabular}{lccc}
\hline \multicolumn{1}{c}{ Concept } & $\begin{array}{c}\text { Pseudo- } \\
\text { problem }\end{array}$ & $\begin{array}{c}\text { Real- } \\
\text { problem }\end{array}$ & Frequency \\
\hline $\begin{array}{l}\text { Area of a } \\
\text { rectangle }\end{array}$ & 10 & 11 & 21 \\
$\begin{array}{l}\text { Fraction } \\
\text { operations }\end{array}$ & 4 & 4 & 8 \\
$\begin{array}{l}\text { Linear equation } \\
\text { in two variables }\end{array}$ & 0 & 1 & 1 \\
$\begin{array}{l}\text { A problem } \\
\text { links two or } \\
\text { three defined } \\
\text { concepts }\end{array}$ & 0 & 0 & 0 \\
\hline \multicolumn{1}{c}{ Total } & 14 & 16 & 30 \\
\hline
\end{tabular}

Based on the table, it is obvious that the majority of the problems were related to the area of a rectangle $(70.00 \%)$ and fraction operations $(26.67 \%)$. There was only one problem showing the 'linear equation in two variables' concept.

\section{Simple Problems Using Common/Everyday Objects}

There was a high level of variation found in the problems posed by participants. Nevertheless, the problems were simple and not challenging. The 'area of a rectangle' problems mostly asked about how to determine the area of a rectangle. There were also problems that asked about the perimeter of a rectangle, the width of a rectangle if the area and the length are known, and the number of tiles used to cover a particular floor area. These types of problems only require the application of standard procedures, such as the formulas to determine the area or perimeter of a rectangle. In fact, these problems failed to incorporate other geometry concepts or other mathematical topics. Problems related to fraction operations covered addition, subtraction, and multiplication of two or more fractions.

The objects of the problems related to the area of a rectangle were commonly found around the participants, such as blackboard, table, window, banner, floor, land, field, or swimming pool. The same thing was discovered in the problems related to fraction operation. The objects used by participants were money, a shopping list, number of students, or the length or weight of something. The problem that showed the concept of linear equation in two variables employed the purchase price as an object. Figure 2. presents some instances of simple problems that used familiar objects proposed by the participants. 


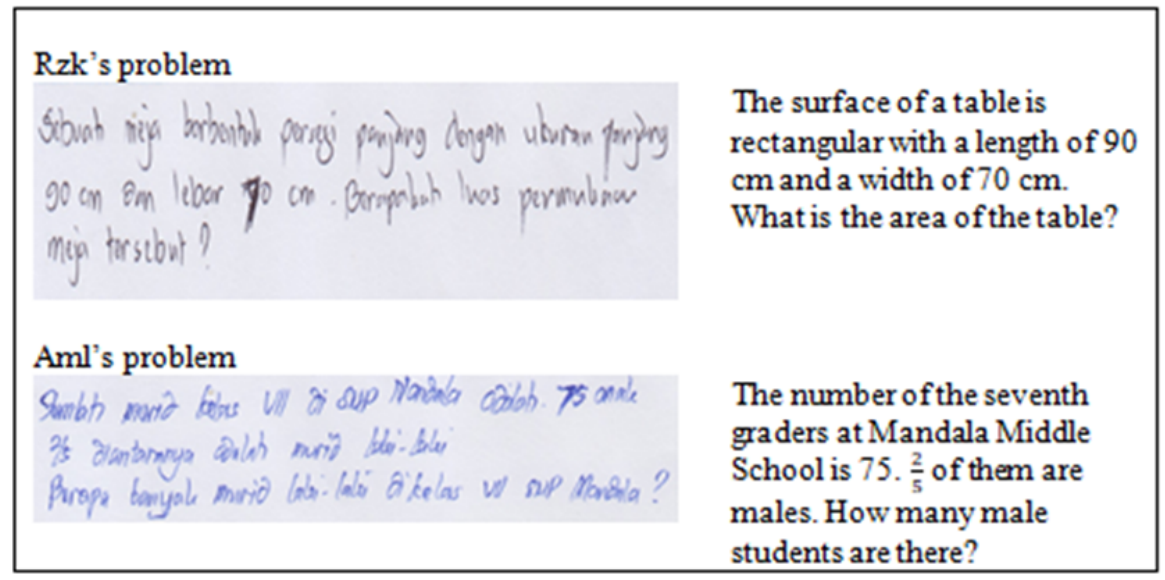

Figure 2. Simple problems using everyday objects

\section{Pseudo-problems: Problems Irrelevant to Everyday Life Reality}

Of the 30 problems involving real-life context posed by the participants in this study, 14 were categorized as pseudo-problems. The everyday objects found in the problems only served as embellishment or accessories, which means that the objects are common in everyday life. However, the use of the objects in the problems was irrelevant. Figure 3. presents some instances of the pseudo-problems posed by the participants.

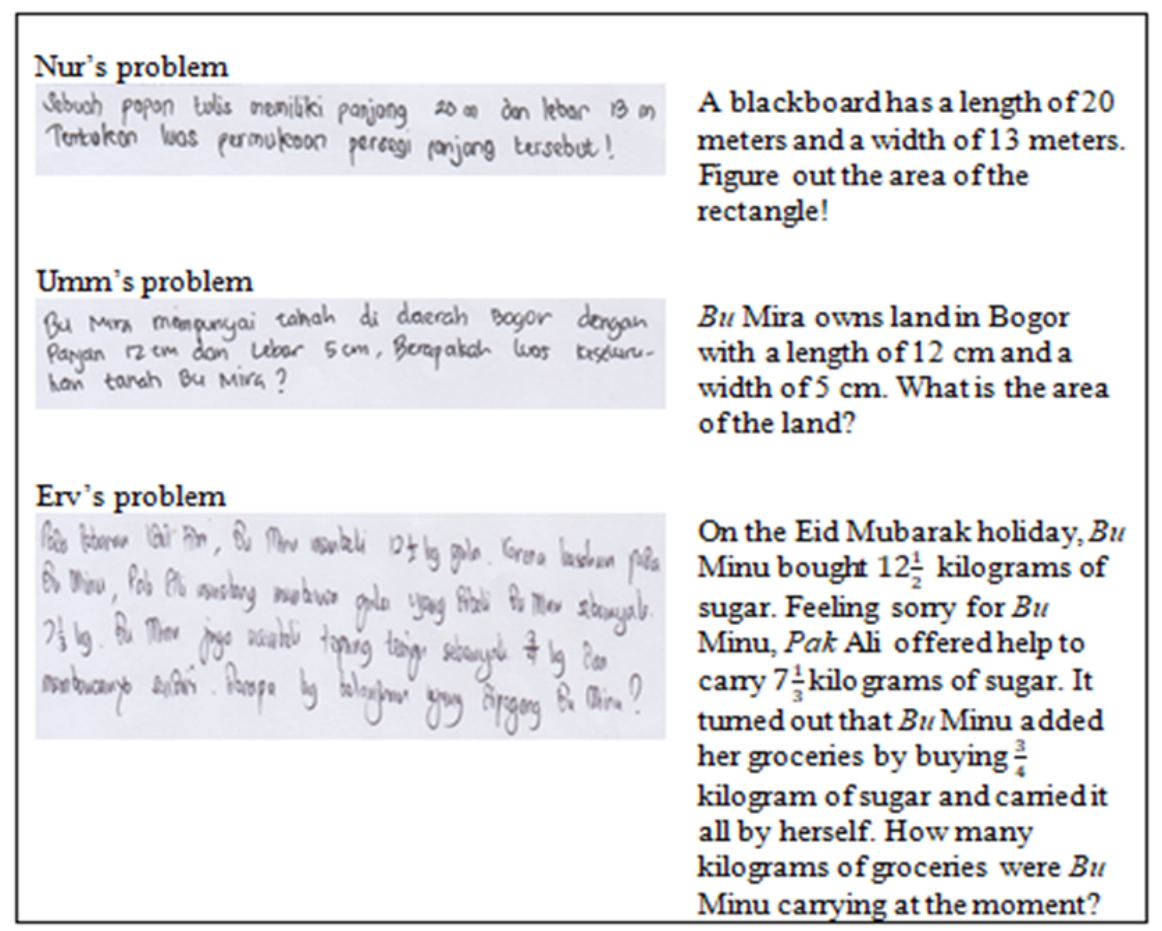

Figure 3. Pseudo-problems

Nur, indeed, used a familiar object (blackboard) in her problem, yet ignored the reasonable size of the object. The length $(20 \mathrm{~m})$ and width $(13 \mathrm{~m})$ of the object may be considered too big for a normal blackboard. In fact, she actually realized that a blackboard with the size could never be found in real life. However, she thought that the size would not matter because the blackboard referred to in the problem is not an actual blackboard.
Interviewer: Could you please look at your problem? What is your thought on a blackboard with a length of 20 meters?

Nur : I don't think it is an appropriate length for a blackboard, $\mathrm{Bu}$, but the blackboard (I referred to) in the problem is not real. It is only created for a mathematical problem in the context of real life. 
Umm provided no clear information on the geometric shape of the land. However, the length and width of the land already explained that the shape is rectangular. She used centimeters instead of meters as the metric unit of measurement. At the beginning of the interview, she was not aware that centimeters were not appropriate in this context. Yet, in the end, she demonstrated an attempt to change the measurement unit into meters.

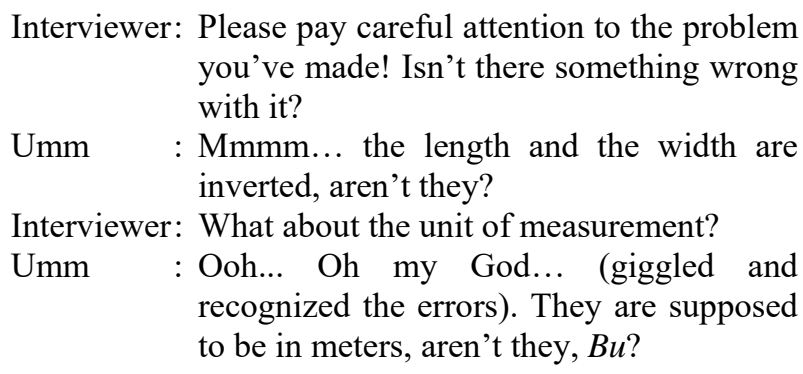

The context of Erv's problem can be still considered appropriate as sugar is normally packed in 1 kilogram-bags or $\frac{1}{2}$ kilogram-bags. However, the next sentence which said, "Pak Ali offered help to carry $7 \frac{1}{3}$ kilograms of sugar" sounds odd since $\frac{1}{3}$ is not appropriate in this context. It is difficult to imagine that Pak Ali had to open a 1 kilogram-sugar bag and divide it into $\frac{1}{3}$ kilogram to be carried with the other 7 kilogram-bags. In the interview, the participant explained that when he created the problem, he only focused on the process of solving the fraction operations instead of the context.
Interviewer: Can you please pay attention to the problem you've made? Pak Ali was carrying $7 \frac{1}{3}$ kilograms of sugar, while sugar is normally packed in 1 kilogrambags or $\frac{1}{2}$ kilogram-bags. So, if you used $7 \frac{1}{3}$, it means that Pak Ali had to open a 1 kilogram-sugar bag and divide it into $\frac{1}{3}$ kilogram. Do you think this should be considered in the problem or not?

Erv : It depends, Bu. If the problem is associated with real-life context, then it needs to be considered. But, if the fractions are only used in mathematical problems or only used as an example of solving fraction operations, I don't think it mattered. This problem is created only to train students' skills in solving either proper or mixed fraction operations.

The three pseudo-problems presented by the participants concentrated on the mathematical numbers that can be operated using a known procedure or formula. The participants, indeed, used real objects in the problems but ignored the relevance between the objects and the context. Based on the results of the interview, there was only one participant (Umm) who was aware of the connection between the object and the context. On the other hand, Nur and Erv were more focused on mathematical operations and more likely to ignore the connection.

\section{Real-problems: Problems Relevant to Everyday Life Reality}

Sixteen real-problems were found among the 30 problems involving real-life context submitted by the participants. Figure 4. presents the instances of realproblems posed by the participants.

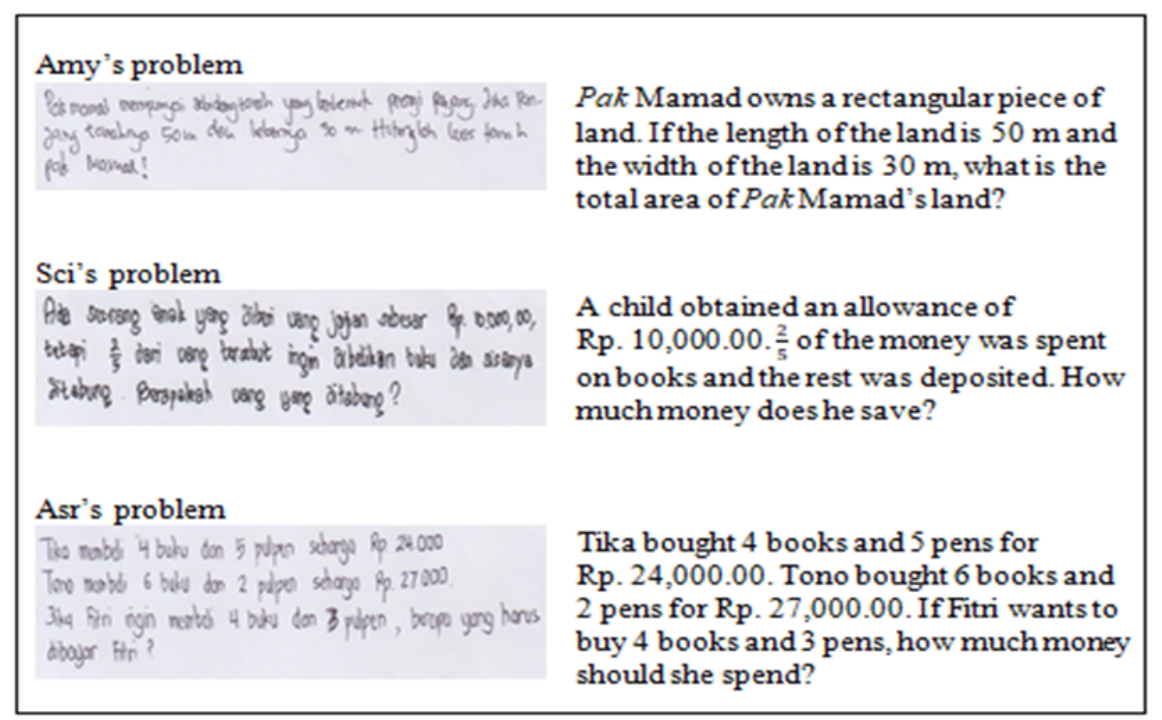

Figure 4. Real-problems 
The objects, the numbers, and the connection between the objects and the numbers in the problems posed by Amy and Sci were relevant to the context. The number that Sci used in the problem was considered appropriate because $\frac{2}{5}$ from 10,000 will yield a reasonable result (in rupiahs). If she considered using $\frac{1}{3}$ in the problem, then the result will be illogical (Rp. 3,333.33). The result of the interview with Amy uncovered the fact that she was aware to create a problem relevant to the context of real life. When she was confronted with a question, "what if the unit of measurement is changed into centimeters", she answered, "it does not make sense".

Amy : If the length of the land is changed into $50 \mathrm{~cm}$, students will probably find out that the measurement is appropriate. When I created the problem, I hoped that students were able to understand it better and solve it more easily. If I were about to use centimeters as the unit of measurement, then I would not use a piece of land as the object.

Unlike Amy, Sci based her decision on numbers selection on the simplicity of the calculation. She explained why she used $\frac{2}{5}$ instead of other fractions (e.g., $\frac{2}{3}$ ) in the following excerpt.

Sci : I considered $\frac{2}{5}$ easy for multiplication. If the number $(10,000)$ is divided (by five), the result will be without a remainder.

Asr was the only participant who posed a problem showing the 'linear equation in two variables' concept. During the process of solving the problem, Asr made some revisions. Figure 5. shows Asr's revisions in her solution to the problem she made.

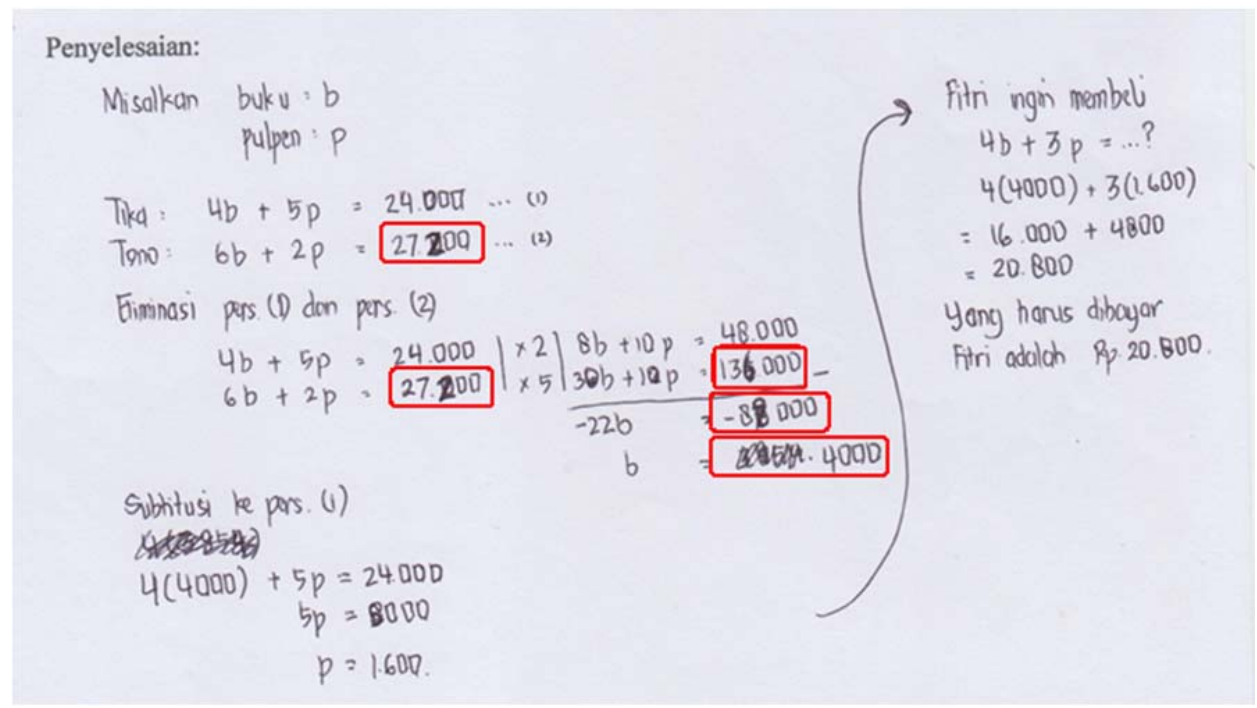

Figure 5. Asr's revisions

Asr constructed a mathematical model from the problem sentence using variable $b$ for the book price and variable $p$ for the pen price. Next, she employed an elimination method to equations $4 b+5 p=24,000$ and $6 b+2 p=27,000$ to obtain $b=3,954$. The value of $b$ was the result of rounding to the nearest unit. After that, she changed some numbers in the calculation. These changes can be seen in Figure 5. Based on the interview, it was found that Asr made the changes for the sake of simplifying the calculation. Asr explained that she solved the problem and found $b=3,954.545$. She rounded it to 3,954 . Then, she thought that it was easier to operate at 4,000 than 3,954. After that, she changed some numbers in the calculation to obtain $b=4,000$. She did not mention reasons as "Rp. 3,954.545 is not compatible with the price of books on the market" or other similar reasons that are related to a real-life context. Therefore, these changes were not based on
Asr's awareness of the inappropriateness of the prices in a real-life context.

\section{Discussion and Conclusion}

Problems that were presented by the participants in this study were not much different from the problems found in the textbooks, such as figuring out the area of a rectangle or problems related to fraction operations. As a matter of fact, problems that were posed by the pre-service teachers in this study are not complex problems that require analysis, reasoning, or the ability to link two mathematical concepts. These problems are considered as primitive problems [12], [16], assignment proposition problems [16], and zero semantic relation problems that can be solved by merely utilizing information stated in the problems [16]. In short, the problems are not challenging. 
The complex and challenging problems could encourage the students to apply concepts and procedures into a new situation [7], [8], [27]. High quality mathematical problems can accommodate student thinking skills, challenge students' ability to use their knowledge and experiences, and strengthen their concept mastery. Ironically, the pre-service teachers in this study were not actually aware of that and chose to pose simple problems. Seven participants presented more than one problem, but the concepts of the problems were not interconnected. None of the participants attempted to propose a theme to link the problems or connect two or three concepts in the presented problems. The results of the interview suggested that such simple problems were intentionally created as these types of problems were easier to understand and simpler to solve. [28] also found in their study that pre-service teachers constructed simple and exercise type problems. Therefore, pre-service teachers need to possess the ability to present complex and challenging problems. It is important since the students need to be motivated to use and connect their existing mathematical knowledge and experiences to solve mathematical problems.

Students have a tendency to create connections between their non-mathematical experiences and problems they encounter in the textbooks [11], [12]. Therefore, the use of familiar objects in a mathematical problem can help the students solve the problem. It is realized by pre-service elementary school teachers in this study. Most of them raised problems containing the context of daily life. The objects of the problems were often found in everyday life, such as blackboard, field, cake, flour, sugar, pen, or book. Problems involving everyday life context were classified into pseudo-problems and realproblems. Real-problems were more frequently found in the participants' submission compared to pseudo-problems.

[29] indicated that some pre-service teachers assumed they do not need to consider the context of the problem in a solving problem. A related finding also happened in a posing problem. Some participants in this study focused on numbers that can be operated using known mathematical procedures or formulas. They decided to employ real objects in their mathematical problems, but ignored the connection between the objects, the numbers (amount or measure of the object), and the relevance to the context of real life. The real objects were only utilized as embellishment or accessories. As a result, some of them created pseudo-problems. Some others created real-problems, but unfortunately, not all of them made it based on their awareness of problemcontext relevance. Their selection of real-life objects and numbers was considered as a mere natural coincidence. Based on the interview, their decision on using particular everyday objects and numbers was not rooted in their awareness of making a connection between the objects and the context, but for the sake of simplifying the calculation.

Pre-service teachers often deal with many difficulties when asked to present a mathematical problem. One of which is to create mathematical problems which accommodate the object-context relevance. In this study, the participants integrated real-life objects into mathematical problems, but the numbers or units of measurement used in the problems are somewhat inappropriate for the context. A similar finding is also discussed by [19], [20] and [30]. [30] found that in most cases, pre-service teachers failed to use daily life stories to express the data in the graphs. [19] pointed out four blocks of difficulties experienced by pre-service teachers in posing problems. One of them was to make the problems more relevant to the reality of the students' everyday lives. [20] also found that pre-service elementary teachers posed problems that were not related to the daily life situation.

Pre-service elementary school teachers should be extremely careful in selecting objects or stories used in mathematical problems because the elementary school students will relate their knowledge and reallife experiences to the problems. The pre-service elementary school teachers' awareness of creating challenging mathematical problems needs to be promoted so that the students' ability to understand mathematical concepts can be strengthened. The awareness of the pre-service elementary school teachers to incorporate relevant real-life objects and numbers also needs to be improved. Their ability to posing the problem that is relevant to the students' knowledge and experiences outside mathematics needs to be enhanced.

A suggestion for educational practices is to explicitly include problem posing activity in mathematics classrooms for the pre-service elementary school teachers. It can give more opportunities to improve their problem posing abilities. 


\section{Acknowledgements}

This research was supported by the Lembaga Pengelola Dana Pendidikan (Endowment Fund for Education) Republic of Indonesia (grant no. 20161141081900).

\section{References}

[1]. Soedjadi, R. (1999). Kiat Pendidikan Matematika di Indonesia (Konstalasi Keadaan Masa Kini Menuju Harapan Masa Depan) Jakarta: Dirjen Dikti Depdikbud.

[2]. Bell, F. H. (1978). Teaching and learning mathematics (in secondary schools). WC Brown Company.

[3]. Febriana, D. F., Amin, S. M., \& Wijayanti, P. (2019, February). Concreteness fading process of elementary school students based on mathematical ability. In Journal of Physics: Conference Series (Vol. 1157, No. 4, p. 042049). IOP Publishing.

[4]. Sumantri, M. S., \& Satriani, R. (2017). The effect of formative testing and self-directed learning on mathematics learning outcomes. International Electronic Journal of Elementary Education, 8(3), 507-524.

[5]. Hobbs, L., \& Davis, R. (2013). Narrative pedagogies in science, mathematics and technology. Research in Science Education, 43(3), 1289-1305. doi: 10.1007/s11165-012-9302-5

[6]. Soto y Koelemeijer, G., Janssen, F. J. J. M., \& Kop, P. M. G. M. (2018). Shaping Mathematics into Stories by means of Propp's Narratemes. Eurasia Journal of Mathematics, Science and Technology Education, 14(2), 657-669. https://doi.org/10.12973/ejmste/80629

[7]. Downton, A., \& Sullivan, P. (2017). Posing complex problems requiring multiplicative thinking prompts students to use sophisticated strategies and build mathematical connections. Educational Studies in Mathematics, 95(3), 303-328. doi: 10.1007/s10649-017-9751-x

[8]. Ferrini-Mundy, J. (2000). Principles and standards for school mathematics: A guide for mathematicians. Notices of the American Mathematical Society, 47(8).

[9]. Timmerman, M. A. (2014). Making connections: Elementary teachers' construction of division word problems and representations. School Science and Mathematics, 114(3), 114-124.

doi: $10.1111 /$ ssm. 12059

[10].McAllister, C. J., \& Beaver, C. (2012). Identification of error types in preservice teachers' attempts to create fraction story problems for specified operations. School Science and Mathematics, 112(2), 88-98. doi: 10.1111/j.1949-8594.2011.00122.x

[11].Ellerton, N. F. (1986). Children's made-up mathematics problems - a new perspective on talented mathematicians. Educational Studies in Mathematics, 17(3), 261-271.

doi: 10.1007/BF00305073
[12].Har, Y. B. (2009). Mathematical problem posing in Singapore primary schools. In Mathematical Problem Solving: Yearbook 2009, Association of Mathematics Educators (pp. 102-116).

[13]. Ellerton, N. F. (2013). Engaging pre-service middleschool teacher-education students in mathematical problem posing: development of an active learning framework. Educational Studies in Mathematics, 83(1), 87-101. doi: $10.1007 / \mathrm{s} 10649-012-9449-\mathrm{z}$

[14].Crespo, S., \& Sinclair, N. (2008). What makes a problem mathematically interesting? Inviting prospective teachers to pose better problems. Journal of Mathematics Teacher Education, 11(5), 395-415. doi: 10.1007/s10857-008-9081-0

[15].Chua, P. H., \& Wong, K. Y. (2012). Characteristics of Problem Posing of Grade 9 Students on Geometric Tasks. Mathematics Education Research Group of Australasia.

[16].Silver, E. A., \& Cai, J. (1996). An analysis of arithmetic problem posing by middle school students. Journal for research in mathematics education, 521-539. doi: 10.2307/749846

[17].Christou, C., Mousoulides, N., Pittalis, M., PittaPantazi, D., \& Sriraman, B. (2005). An empirical taxonomy of problem posing processes. $\mathrm{Zdm}, 37(3)$, 149-158. Doi: 10.1007/s11858-005-0004-6

[18].Marhayati. (2015). Karakteristik proses berpikir kreatif siswa dalam pengajuan soal matematika [characteristics of students' creative thinking processes in posing mathematical problems]. (Unpublished doctoral's dissertation). Universitas Negeri Malang, Indonesia.

[19].Mallart, A., Font, V., \& Diez, J. (2018). Case study on mathematics pre-service teachers' difficulties in problem posing. Eurasia Journal of Mathematics, Science and Technology Education, 14(4), 14651481.

doi: $10.29333 /$ ejmste/83682

[20].Prayitno, L. L., Purwanto, P., Subanji, S., \& Susiswo, S. (2018). Identification Errors of Problem Posed by Prospective Primary Teachers About Fraction Based Meaning Structure. International Journal of Insights for Mathematics Teaching (IJOIMT), 1(1), 76-84.

[21].Silver, E. A. (1994). On mathematical problem posing. For the learning of mathematics, 14(1), 1928.

[22].Stoyanova, E. N. (1997). Extending and exploring students' problem solving via problem posing: A study of Years 8 and 9 students involved in Mathematics Challenge and Enrichment Stages of Euler Enrichment Program for Young Australians. Edith Cowan University.

[23].Schroeder, T. L. (1993). Mathematical Connections: Two Cases from an Evaluation of Students' Mathematical Problem Solving.

[24]. Creswell, J. W. (2012). Educational research: planning. Conducting, and Evaluating..

[25].Suter, W. N. (2011). Introduction to educational research: A critical thinking approach. SAGE publications. 
[26].Miles, M. B., Huberman, A. M., \& Saldana, J. AM (2014). Qualitative Data Analysis A Methods Sourcebook. AM Matthew B. Miles, Qualitative Data Analysis: A Methods Sourcebook, 10..

[27]. Shimizu, Y. (2009). Japanese approach to teaching mathematics via problem solving. In Mathematical Problem Solving: Yearbook 2009, Association of Mathematics Educators (pp. 89-101).

[28].Şengül, S., \& Katranci, Y. (2015). Free problem posing cases of prospective mathematics teachers: Difficulties and solutions. Procedia-Social and Behavioral Sciences, 174, 1983-1990. doi: 10.1016/j.sbspro.2015.01.864.
[29].Southwell, B., \& Penglase, M. (2005). Mathematical knowledge of pre-service primary teachers. International Group for the Psychology of $M$ athematics Education, 209.

[30].Tuğrul, K. A. R. (2016). Prospective middle school mathematics teachers' knowledge of linear graphs in context of problem-posing. Editors, 8(4), 643-658. 